\title{
In vitro embryo production in buffaloes: from the laboratory to the farm
}

\author{
Diego Fernando Dubeibe Marin ${ }^{1, \S}$, Eduardo Baia de Souza ${ }^{1}$, Vanessa Cunha de Brito ${ }^{1}$, \\ Carlos Vinicius Nascimento ${ }^{2}$, Anelise Sarges Ramos ${ }^{3}$, Sebastião Tavares Rolim Filho ${ }^{3}$, Nathalia Nogueira da \\ Costa $^{1}$, Marcela da Silva Cordeiro ${ }^{4}$, Simone do Socorro Damasceno Santos ${ }^{1}$, Otavio Mitio Ohashi ${ }^{1}$ \\ ${ }^{1}$ Instituto de Ciências Biológicas, Universidade Federal do Pará (UFPA), Belém, Pará, Brazil. \\ ${ }^{2}$ BUBRAS, Belém, Pará, Brazil. \\ ${ }^{3}$ Setor de Reprodução Animal, Universidade Federal Rural da Amazônia (UFRA). Belém, Pará, Brazil. \\ ${ }^{4}$ Instituto Federal de Educação, Ciência e Tecnologia do Pará (IFPA), Belém, Pará, Brazil.
}

\begin{abstract}
Transvaginal follicular aspiration technique together with in vitro embryo production are the biotechnological alternatives currently available to support genetic improvement breeding programs in buffalo species. However, aspects related to animal management, lack of knowledge of the metabolic needs and biochemical peculiarities of gametes and embryos, as well as the reproductive physiology characteristics have hampered progress in the results. Despite the low availability of good quality oocytes collected after OPU in donors as a physiological characteristic of buffalo species, high rates of oocyte maturation, modest embryo cleavage, blastocyst production and pregnancy rates after transvaginal embryo transfer in recipients could be obtained in buffalo in vitro embryo production programs. The results of implementing an in vitro embryo production program in buffaloes in the northern region of Pará state, Brazil, and results published by other groups demonstrate the feasibility of implementing this biotechnology in the routine of breeding programs. Nevertheless, in order to achieve better and consistent results, it is necessary to deepen the knowledge on the peculiarities of reproductive biology in this specie. Selection of donor animals based on ovarian size and ovarian follicular reserve and on the rate of blastocyst production is presented as an effective alternative to increase the efficiency of the in vitro embryo production technique applied to the buffalo species.
\end{abstract}

Keywords: buffalo, breeding programs, in vitro embryo production.

\section{Introduction}

Considering the limited success in embryo recovery rates with multiple ovulation and embryo transfer programs (MOET) in bubaline species (Drost, 2007; Baruselli et al., 2013), transvaginal follicular aspiration technique (Ovum Pick Up [OPU]), together with in vitro embryo production are the biotechnological alternatives currently available to support breeding programs in this species (Gimenes, 2010; Gasparrini, 2013; Saliba et al., 2013; Galli et al., 2014; Ferraz et al., 2015; Ohashi et al., 2017).

Implementation of the OPU technique in buffalo species was first reported in 1994 (Boni et al.,
1994), and the first buffalo produced using the combination of OPU and in vitro fertilization (IVF) techniques was reported by Galli et al., 1998. Since that time, different laboratories with scientific and/or commercial character have worked in the search to improve the embryo production rates.

However, some aspects related to animal management, a lack of knowledge on the metabolic needs and biochemical peculiarities of gametes and embryos, as well as the characteristics of their reproductive physiology have hampered progress in the results (Gasparrini, 2007; Ohashi et al., 2017).

The present review describes some of the particularities of the buffalo species in relation to the in vitro embryo production technique and the strategies which have been adopted over time in the search to improve embryo production rates, the quality of produced blastocysts and the progress in embryo cryopreservation technics. In addition, some results are described as a product of implementing an in vitro embryo production program in a commercial buffalo breeding system in the northern region of Pará state, Brazil.

\section{Cumulus-oocyte complex (COCs) from live donors}

In contrast to the bovine zebu breed, females of the buffalo species show a lower ovarian follicular reserve ( $\sim 19000$ vs $\sim 150000$, for buffalo and bovine species respectively) (Danell, 1987; Gasparrini, 2002; Santos et al., 2013) and a smaller number of follicles recruited in each wave of follicular growth (around 5 8) (Baruselli et al., 1997). As a consequence, oocyte recovery rates achieved by OPU are usually lower in buffalo (around 14 vs 37 oocytes/animal for buffalo and bovine [zebu breed] species, respectively) (Gimenes, 2010).

Similarly, the rate of good quality oocytes recovered with morphological characteristics of structures with the possibility of being successfully fertilized is lower $(\sim 9 \mathrm{COCs} /$ animal $)$ than that obtained in zebu bovine species (around 27 COCs/animal) (Gimenes, 2010; Suresh et al., 2009). The high incidence of naturally occurring follicular atresia in the ovaries of the buffaloes could be at least partly responsible for this peculiarity (Ocampo et al., 1994; Perera, 2011; Santos et al., 2013).

In addition, the number of follicles available for each aspiration session and the quality of the 
recovered structures are characteristics that may be influenced by climatic seasons. It has been observed that the quantity $(6.2 \pm 1.4$ vs $2.7 \pm 0.9$ oocytes/ovary during winter and summer seasons, respectively) and quality of oocytes decreases significantly during the hottest periods of the year (Abdoon et al., 2014).

However, evidence indicates that these are highly variable characteristics among individuals, but at the same time they are quite repeatable attributes within the same animal over several OPU sessions. Therefore, it is possible to predict the potential of each donor, not only in the oocyte production rate per OPU session, but also for its subsequent embryo production through this biotechnology (Gasparrini et al., 2014b).

The frequency at which OPU sessions are performed could affect the number of follicles available for aspiration (Ferraz et al., 2015). For example, Konrad et al. (2017) observed that 14-day intervals between OPU sessions would increase the amount of recovered oocytes $(4.5 \pm 0.49 /$ animal $)$ compared to 7 -day intervals (2.8 \pm 0.45 /animal). However, in the aspirations performed every 14 days, the availability of good quality oocytes decreases, therefore generally speaking the frequency of aspirations could affect the oocyte recovery rate, but would not modify the final blastocyst production rate (Konrad et al., 2017).
Finally, the length of time that donors undergo OPU may negatively affect the quantity, but mainly the quality of the recovered COCs, leading to a significant decrease in the blastocyst production when the OPU sessions are maintained uninterrupted for a long time (Neglia et al., 2011).

In our experience, by following a regimen of follicular aspiration sessions every 15 days over a period of five months of work (Table 1), an average of $13.5 \pm 5.6$ follicles were aspirated from each animal, from which $10.2 \pm 6.5$ structures were recovered and 5.2 \pm 3.9 COCs selected to continue the in vitro maturation process, but only $3.1 \pm 2.6 \mathrm{COCs} /$ animal/aspiration session were considered viable according to the morphological characteristics of the COCs (Di francesco et al., 2012).

In these conditions, $76 \%$ of the structures were retrieved from the total of available follicles to be aspirated. However, only $51 \%$ of this total could be used for IVM purposes, and finally only $23.4 \%$ of the COCs were considered viable for IVF (oocytes with more than two layers of cumulus cells). These results confirm that one of the main obstacles in implementing this biotechnology in the buffalo species is related to the low availability of good quality oocytes as raw material for the in vitro embryo production process (Table 1).

Table 1. Mean number and its equivalent in proportion of the number of follicles and structures recovered by follicular aspiration guided by ultrasonography/animal/session, in buffaloes from the northern region of the Pará state, Brazil.

\begin{tabular}{lcccc}
\hline & Aspirated follicles & Recovered structures & COCs taken to IVM & Viable COCs \\
\hline (n) & $13.5 \pm 5.6$ & $10.2 \pm 6.5$ & $5.2 \pm 3.9$ & $3.1 \pm 2.6$ \\
$(\%)$ & - & $76 \%$ & $51 \%$ & $23.4 \%$ \\
\hline
\end{tabular}

Values of number (n) represent mean \pm standard deviation. The proportion (\%) of COCs taken to IVM and viable COCs was calculated from the total of recovered structures. COCs: cumulus-oocyte complexes; IVM: in vitro maturation.

Additionally, the average of COCs recovered and considered as viable/donor/OPU session at the beginning of the project was 2.5. Upon selection which was subsequently performed through gynecological evaluation by trans-rectal palpation and ultrasonography, buffaloes were selected from the herd that had a larger ovarian size and a follicular population above 10 follicles/ovary (Ohashi et al., 2017). Thus, a mean of 3.6 viable COCs/donor/OPU session was achieved in the subsequent stages, demonstrating that the repeatability of the variables associated with the amount of aspirable follicles/animal, represents an usable alternative in the search to increase the availability of viable COCs.

\section{In vitro maturation (IVM)}

Buffalo oocytes reach high maturation rates $(\sim$ $80 \%$ ) when taken to culture in laboratory conditions, similar to those obtained in bovine species (Santos et al., 2002b; Suresh et al., 2009; Gimenes, 2010). Traditionally, the medium and culture conditions are the same as those used for bovine oocytes (Galli et al., 2003).

The presence of an appropriate layer of cumulus cells along with the addition of antioxidant substances and growth factors have been considered as essential factors to obtain an adequate nuclear and cytoplasmic maturation process in buffalo oocytes (Gasparrini et al., 2006; Singhal et al., 2009). According to Surresh et al. (2009), the best maturation, cleavage and embryo production rates in buffalo species are achieved when oocytes with a proper cumulus cell layer from large follicles and in the cold seasons of the year are cultured in TCM-199 media supplemented with fetal bovine serum (FBS), FSH and cysteamine (Suresh et al., 2009).

In turn, the time required for complete nuclear maturation of oocytes in vitro, which means the arrival of the chromosomes to Metaphase II stage, could be from 18 to $24 \mathrm{~h}$ (Santos et al., 2002a; Gasparrini et al., 2008). Particularly, the increase in the maturation period of buffalo oocytes in the laboratory is related to a decrease in the blastocyst production rates (Oba and Camargos, 2011). Maturation periods longer than 24 hours may lead to inappropriate chromatin configurations, oocyte aging and a decrease in competence development, thus demonstrating more sensitivity to the effects of time on oocyte quality than other species (Kumar and Anand, 2012). 


\section{In vitro fertilization (IVF)}

In general, cleavage rates after the in vitro fertilization process of buffalo oocytes are low ( 45$50 \%$ ) (Suresh et al., 2009) compared to those obtained in bovine species $(\sim 70 \%)$ (Sales et al., 2015). This step in the embryo production process is highly influenced by the characteristics of the semen used (Galli et al., 2001).

At the beginning of applying the in vitro embryo production technique in buffaloes, low quality of the frozen/thawed semen was considered one of the main limiting factors for applying the technique in this species (Totey et al., 1992). However, improvements in processing and freezing buffalo semen circumvented this difficulty. Still, differences among bulls in sperm survival after the cryopreservation process also reflect differences in embryo production rates under laboratory conditions (Gasparrini, 2002).

The methods for sperm preparation prior to the in vitro fertilization process, which include washing and sperm capacitation procedures, are traditionally the same used for embryo production in the bovine species (Parrish, 2014). Heparin has been chosen to be used as the agent for inducing in vitro sperm capacitation in most of the described protocols. However, other substances such as nitric oxide donors (Jagan et al., 2012), methyl- $\beta$-cyclodextrin (Gasparrini et al., 2014a), osteopontin (Boccia et al., 2013) or progesterone (Boccia et al., 2006), have shown promising results as alternatives to heparin for inducing sperm capacitation in buffaloes.

The co-incubation period of oocytes with sperm cells should be adequate to enable correct induction of plasma membrane vesiculation and the complete acrossomal reaction. Appropriate times of not less than 4-6 $\mathrm{h}$ have been described, however, it was reported that this time should be extended for at least 16 $\mathrm{h}$ in order to maximize blastocyst production rates (Kumar and Anand, 2012).

On the other hand, a prolonged co-cultivation period could hinder the final blastocyst production rate. Cultivation periods greater than $20 \mathrm{~h}$ could increase polyspermy incidence, thus reducing the embryo production rates (Gasparrini et al., 2008).

A determinant factor for a good result in the in vitro fertilization process is related to the quality and competence characteristics of the oocytes, both acquired during the maturation process. Differences in cleavage and production of blastocyst rates produced from oocytes activated by parthenogenesis as compared to laboratory-fertilized oocytes could indicate that the low rates of development during cultivation would be due to deficiencies in the male gamete, rather than the quality of oocytes (Yang et al., 2012). However, evidence that cleavage rates could be increased by supplementation with substances with antioxidant capacity during IVM could indicate that the consequences of fertilization in the laboratory not only depend on the quality of sperm, but also on the two gametes involved in the process (Gasparrini et al., 2006).

Finally, differences in the sperm concentration used to obtain adequate cleavage rates may be necessary in the in vitro embryo production systems of buffaloes compared to those used in the same process applied to the bovine species (Neglia et al., 2003).

During our particular experience, conventional frozen/thawed semen from 2 different bulls were used for the in vitro fertilization process, and in some cases the result was evaluated with sexed semen. For this step of the procedure, a concentration of 2 million spermatozoa $/ \mathrm{mL}$ was used in previously matured oocytes for $20 \mathrm{~h}$ in TCM-199 medium supplemented with gentamicin $(50 \mu \mathrm{g} / \mathrm{mL})$, epidermal growth factor (EGF) $(20 \mu \mathrm{g} / \mathrm{mL}), \beta$-mercaptoethanol $(50 \mu \mathrm{M})$, FSH $(0.5 \mu \mathrm{g} / \mathrm{mL})$, LH $(50 \mu \mathrm{g} / \mathrm{mL})$, ITS $(10 \mu \mathrm{L} / \mathrm{mL})$, sodium pyruvate $(0.2 \mathrm{mM})$ and $10 \% \mathrm{FBS}$.

Although the cleavage rate was not evaluated, the final blastocyst production assessed over the total of structures put in maturation showed similar percentages between bulls $(21.8 \pm 4.3 \%$ vs $23 \pm 3.0 \%$, mean \pm s.e. $)$, whereas the result observed for sexed semen was $17 \pm$ $6.5 \%$ (mean \pm s.e.). Differences in the quality of sperm cells from conventional semen with respect to sexed semen as a result of the changes induced during the sperm selection process could explain these results (Rath et al., 2009; Balao da Silva et al., 2012).

\section{In vitro culture (IVC)}

Different culture approaches have been tested for buffalo embryos. Procedures such as embryo culture in sheep oviducts (Galli et al., 1998), somatic cell coculture systems (Dantas, 2002), use of culture media supplemented with blood sera or semi-defined media supplemented with BSA (Wadhwa et al., 2009) have been evaluated in the in vitro production of embryos. However, regardless of the system used, blastocyst formation rates are usually lower than those achieved in cattle (around 22\% vs 40\%, for buffalo and bovine species, respectively) (Cavalieri et al., 2018; Suresh et al., 2009).

The lack of information about metabolic and biochemical needs of buffalo embryos has made it difficult to develop suitable culture media for the species. Moreover, the observed improvements in the blastocyst production rates could mainly be due to changes in the in vitro maturation and fertilization systems, rather than changes tested during the culture period (Gasparrini, 2013). Embryos of the buffalo species develop 12-24 $\mathrm{h}$ faster than bovine embryos under in vitro or in vivo conditions, indicating that the metabolism of these structures has particular features (Galli et al., 2001).

For instance, regarding carbohydrate metabolism, different from that observed in other ruminant species (bovine and ovine), buffalo embryos require glucose for their proper development from the earliest cultivation stages (Suárez Novoa et al., 2011; kumar et al., 2012). It has been shown that relatively high glucose concentrations $(1.5 \mathrm{mM})$ are required during the early development of buffalo embryos around day 4 of cultivation, while a decreased concentration or absence of glucose even in the late cultivation stages did not show deleterious effects 
(Gasparrini, 2013). Supplementation of culture media with high glucose concentrations $(5.6 \mathrm{mM})$ during oocyte maturation and embryo culture showed promising results (Kumar et al., 2012).

On the other hand, the substitution of a part of the culture medium during the IVC period as a strategy to renew embryotrophic factors and to remove toxic products derived from the metabolism did not show differences in the blastocyst production rates. Embryos of this specie would be more sensitive to variations in temperature and $\mathrm{pH}$ derived from the handling required to perform the medium exchange, so it is convenient in buffalo in vitro embryo production systems to not modify the culture conditions until the final cultivation period (Palta and Chauhan, 1998).

In our case, the embryos were cultured for 6 days in SOF medium supplemented with $5 \% \mathrm{FBS}$, in an incubator at $38.5^{\circ} \mathrm{C}, 5 \% \mathrm{CO}_{2}, 5 \% \mathrm{O}_{2}$, and $90 \% \mathrm{~N}_{2}$, without carrying out substitutions of culture medium.
The mean blastocyst production per donor/OPU session was $1.2 \pm 1.4$ (Table 2). However, as observed in the standard deviation value, there was high individual variability in embryo production (0-3.5 embryos/animal/OPU), suggesting that the conditions and culture media used adequately fit the needs of some individuals, but may be insufficient to meet the particular circumstances of other animals kept under even the same management conditions.

Through selection of the donors made with reference to the average production rate of embryos, it was possible to increase the average embryo production of $0.7 /$ animal/OPU to 1.2 embryos/animal/OPU. Thus, the selecting individuals based on higher than average blastocyst production rates of animals from the same herd could be a valid strategy to increase embryo production rates by in vitro fertilization, thereby making the genetic breeding programs in the buffalo species that use in vitro embryo production feasible as a tool.

Table 2. Results of implementing an in vitro embryo production program in buffaloes in the northern region of Pará state, Brazil.

\begin{tabular}{lccc}
\hline Result & Total & Average/aspirated donor & $\%$ \\
\hline OPU Sessions & 9 & - & - \\
Embryos produced & 151 & $1.2 \pm 1.4$ & - \\
Embryos/oocytes in IVM & - & - & 23.4 \\
Embryos/viable oocytes & - & - & 39.7 \\
Transferred embryos & 89 & $0.7 \pm 1.2$ & - \\
Pregnancy & 19 & - & $22.2 \pm 12.1$
\end{tabular}

Values of proportion (\%) of embryos produced from oocytes in IVM and from viable oocytes were calculated from the total number of structures and do not represent mean values.

\section{Cryopreservation of embryos}

Cryopreservation is a technique available to support the commercial programs of embryo production in buffalo, since it enables flexibility in embryo transfer schedules by allowing the transfer of embryos to the more favorable seasons of the year, as well as simplifying the transport and marketing of genetic material (Mandawala et al., 2016).

The different cryopreservation methods traditionally used in other domestic species, i.e. the slow freezing and vitrification have been tested on oocytes and embryos from buffalo species (Parnpai et al., 2016). However, particularities which are mainly associated to the content and composition of the intracytoplasmic lipids of gametes and embryos of this species (Boni et al., 1992), have hampered progress in the results.

Comparatively, in terms of cell survival and the subsequent pregnancy rate, vitrification seems to be the most appropriate cryopreservation method for oocytes and buffalo embryos. For embryos, although calves have been obtained through slow freezing, the results of pregnancy rates for embryos derived from in vitro fertilization are low ( $24 \%$ ) (Galli et al., 2012), whereas it has been possible to obtain good pregnancy rates $(\sim 37 \%)$ and healthy offspring through vitrification (Saliba et al., 2013).

Nevertheless, certain factors could influence the response of the embryos to the cryopreservation process. The embryo development stage, the composition of the vitrification solutions and the equilibration times used, as well as the embryo origin (in vivo or in vitro), and the morphological quality of the structures have been pointed out as being responsible for the differences observed in the results (Parnpai et al., 2016).

Evidence indicates that embryos at an advanced development stage (expanded blastocyst) better support cryopreservation compared to younger embryos (Hufana-Duran et al., 2004). The presence of a larger amount of embryonic cells prior to cryopreservation process allows an adequate proportion of blastomers to survive after thawing, thereby ensuring the continuity of embryonic development.

A combination of cryoprotectants with and without ability to penetrate the cytoplasmatic membrane cell are traditionally used in vitrification protocols. Yang et al. (2012) tested different combinations and times, observing that the best results were obtained when embryos were produced in vitro with 6 to 7 days of development, and were vitrified in a solution composed of $20 \%$ ethylene glycol $+20 \%$ DMSO +0.5 $\mathrm{M}$ sucrose (Yang et al., 2012).

Meanwhile, regarding the effect of sex on survival after cryopreservation, Mahmoud et al. (2015) observed that there was a tendency to an increase in post- 
devitrification resistance for male embryos even without a significant difference, suggesting that the higher development velocity of male embryos compared to their female counterparts gives these embryos more cells and consequently greater ability to withstand the deleterious effects of cryopreservation (Mahmoud et al., 2015).

The supplementation of culture media with chemical substances which influence the energy metabolism has been evaluated as a viable alternative to increasing the efficiency of vitrification in mammalian embryos (Held-Hoelker et al., 2017). Adding Lcarnitine during in vitro culture of buffalo embryos showed an increase in post-devitrification survival rates (Verma et al., 2018). Mechanisms associated with this positive response are related to their effect of increasing the intracytoplasmic fatty acids oxidation, in addition to its antioxidant capacity (Abdelrazik et al., 2009), thereby reducing the intracytoplasmic lipid content and protecting embryonic cells of oxidative stress, respectively.

During the course of our project, no methods for embryo cryopreservation were used due to the need to prioritize calf production. In fact, the main difficulty along the project was related to the unstable pregnancy rate after embryo transfer (Table 2). Factors related to the experience of the technician, to the sanitary control of the recipients, the quality of the embryos, and even the management of the recipients, as well as the age and quantity of calves delivered (recipient buffaloes from 4 to 12 years old vs. heifers and cows with no more than one birth) could have influenced the results.

\section{Conclusion}

Although there are still limitations in the development of in vitro embryo production systems in the buffalo species on a commercial scale, publication of papers demonstrating the possibility of obtaining a reasonable blastocyst rate and adequate pregnancy rates after embryo transfer, both fresh as well as cryopreserved, demonstrate the feasibility of implementing this biotechnology in the routine of breeding programs. However, in order to achieve more appropriate and stable results, and thus provide economic viability to the programs, it is necessary to deepen the knowledge on the peculiarities of the reproductive biology of this specie.

Implementation of selection criteria for oocyte donor animals based on anatomical and physiological characteristics such as ovarian size and ovarian follicular reserve, and on the performance of structures collected after fertilization in the laboratory (final rate of blastocyst production), is presented as an effective alternative to increase the efficiency of the in vitro embryo production technique applied to the buffalo species.

\section{Acknowledgments}

BUBRAS company for financial support and partnership. CAPES and MEC for the study grants (DFDM, EBS, ASR).

\section{References}

Abdelrazik H, Sharma R, Mahfouz R, Agarwal A. 2009. L-Carnitine decreases DNA damage and improves the in vitro blastocyst development rate in mouse embryos. Fertil Steril, 91(2):589-596.

Abdoon AS, Gabler C, Holder C, Kandil OM, Einspanier R. 2014. Seasonal variations in developmental competence and relative abundance of gene transcripts in buffalo (Bubalus bubalis) oocytes. Theriogenology, 82(8):1055-1067.

Balao da Silva C, Macías-García B, Morillo Rodriguez A, Gallardo Bolaños JM, Tapia JA, Aparicio IM, Peña FJ. 2012. Effect of Hoechst 33342 on stallion spermatozoa incubated in KMT or Tyrodes modified INRA96. Anim Reprod Sci, 131(3-4):165-71.

Baruselli PS, Mucciolo RG, Visintin JA, Viana WG, Arruda RP, Madureira EH, Molero-Filho JR. 1997. Ovarian follicular dynamics during the estrous cycle in buffalo (Bubalus bubalis). Theriogenology, 47(8):15311547.

Baruselli PS, Soares JG, Gimenes LU, Monteiro BM, Olazarri MJ, Carvalho NAT. 2013. Control of buffalo follicular dynamics for artificial insemination, superovulation and in vitro embryo production. Buffalo Bulletin, 32:160-176.

Boccia L, Attanasio L, Monaco E, Rosa A, di palo R, Gasparrini B. 2006. Effect of progesterone on capacitation of buffalo (Bubalus bubalis) spermatozoa in vitro . Reprod Domest Anim, 41: 311-311.

Boccia L, Francesco S, Di Neglia G, Blasi M, De Longobardi V, Campanile G, Gasparrini B. 2013. Osteopontin improves sperm capacitation and in vitro fertilization ef fi ciency in buffalo ( Bubalus bubalis ). Theriogenology, 80(3): 212-217.

Boni R, Santiella L, Dale B, Roviello S, Di Palo R, Barbieri V. 1992. Maturazione in vitro di oociti buffalini: indagine ultrastrutturale. Acta Med Vet, 38:153-161.

Boni R, Di Palo R, Barbieri V, Zicarelli L. 1994. Ovum pick-up in deep anestrus buffaloes. In: Proc IV world Buffalo Congress, 1994, Napoli, Italy. pp.480482.

Cavalieri FLB, Morotti F, Seneda MM, Colombo AHB, Andreazzi MA, Emanuelli IP, Rigolon LP. 2018. Improvement of bovine in vitro embryo production by ovarian follicular wave synchronization prior to ovum pick-up. Theriogenology, 117:57-60.

Danell B. 1987. Oestrus behaviour, ovarian morphology and cyclical variation in follicular system and endocrine pattern in water buffalo heifers. Uppsalá, Suécia: Swedish University of Agricultural Sciences. Thesis.

Dantas JK. 2002. Desenvolvimento de embriões bubalinos (bubalus bubalis) cultivados in vitro em diferentes meios. [In portuguese]. Belém, Brazil: Universidade Federal do Pará. Thesis.

Di Francesco S, Novoa MVS, Vecchio D, Neglia G, Boccia L, Campanile G, Gasparrini B. 2012. Ovum pick-up and in vitro embryo production (OPU-IVEP) in Mediterranean Italian buffalo performed in different seasons. Theriogenology, 77(1):148-54.

Drost M. 2007. Advanced reproductive technology in 
the water buffalo. Theriogenology, 68(3): 450-453.

Ferraz ML, Sá Filho MF, Batista EOS, Watanabe YF, Watanabe MR, Dayan A, Baruselli PS. 2015. Paradoxical effects of bovine somatotropin treatment on the ovarian follicular population and in vitro embryo production of lactating buffalo donors submitted to ovum pick-up. Anim Reprod Sci, 154:1-7.

Galli C, Duchi R, Crotti G, Lazzari G. 1998. Embryo production by ovum pick up in water buffalo. Theriogenology, 49(1):400.

Galli C, Crotti G, Notari C, Turini P, Duchi R, Lazzari G. 2001. Embryo production by ovum pick up from live donors. Theriogenology, 55(6):1341-1357.

Galli C, Duchi R, Crotti G, Turini P, Ponderato N, Colleoni S, Lazzari G. 2003. Bovine embryo technologies. Theriogenology, 59(2):599-616.

Galli C, Duchi R, Lazzari G, Lagutina I, Colleoni S, Turini P, Berdugo J. 2012. Pregnancies and calves after transfer of in vitro -produced river buffalo embryos after cryopreservation. Reprod Fertil Dev, 24(1):190.

Galli C, Duchi R, Colleoni S, Lagutina I, Lazzari G. 2014. Ovum pick up, intracytoplasmic sperm injection and somatic cell nuclear transfer in cattle, buffalo and horses: from the research laboratory to clinical practice. Theriogenology, 81(1):138-51.

Gasparrini B. 2002. In vitro embryo production in buffalo species: state of the art. Theriogenology, 57(1):237-256.

Gasparrini B, Boccia L, Marchandise J, Di Palo R, George F, Donnay I, Zicarelli L. 2006. Enrichment of in vitro maturation medium for buffalo (Bubalus bubalis) oocytes with thiol compounds: effects of cystine on glutathione synthesis and embryo development. Theriogenology, 65(2):275-87.

Gasparrini B. 2007. In vivo embryo production in buffalo: current situation and future perspectives. Ital $J$ Anim Sci, 6(sup2): 92-101.

Gasparrini B, De Rosa A, Attanasio L, Boccia L, Di Palo R, Campanile G, Zicarelli L. 2008. Influence of the duration of in vitro maturation and gamete coincubation on the efficiency of in vitro embryo development in Italian Mediterranean buffalo (Bubalus bubalis). Anim Reprod Sci, 105(3-4):354-64.

Gasparrini B. 2013. In vitro embryo production in buffalo: Yesterday, today and tomorrow. Buffalo Bulletin, 32(SPEC. ISSUE 1):188-195.

Gasparrini B, Elkhawagah AR, Longobardi V, Sosa GA, Salzano A, Aboul-roos MEA, Zicarelli L. 2014a. Effect of Methyl-B-Cyclodextrin (MBCD) on In vitro Capacitation of Buffalo Frozen/Thawed Sperm. Journal of Buffalo Science, 3(1):12-17.

Gasparrini B, Neglia G, Palo R, Di Vecchio D, Albero G, Esposito L, Zicarelli L. 2014b. Influence of oocyte donor on in vitro embryo production in buffalo. Anim Reprod Sci, 144(3-4):95-101.

Gimenes L. 2010. Taxa de recuperação in vivo e competência in vitro de oócitos bubalinos, zebuinos e taurinos, aspirados em diferentes fases da onda de crescimento folicular [In portuguese]. São Paulo, Brasil: Universidade de São Paulo. Thesis.

Held-Hoelker E, Klein SL, Rings F, Salilew-Wondim D, Saeed-Zidane M, Neuhoff, C, Hoelker M. 2017.
Cryosurvival of in vitro produced bovine embryos supplemented with 1-Carnitine and concurrent reduction of fatty acids. Theriogenology, 96:145-152.

Hufana-Duran D, Pedro PB, Venturina HV, Hufana RD, Salazar AL, Duran PG, Cruz LC. 2004. Postwarming hatching and birth of live calves following transfer of in vitro -derived vitrified water buffalo (Bubalus bubalis) embryos. Theriogenology, 61(78):429-1439

Jagan Mohanarao G, Atreja SK. 2012. Identification of NO induced and capacitation associated tyrosine phosphoproteins in buffalo (Bubalus bubalis) spermatozoa. Res Vet Sci, 93(2):618-623.

Konrad J, Clérico G, Garrido MJ, Taminelli G, Yuponi M, Yuponi R, Sansinena M. 2017. Ovum pick-up interval in buffalo (Bubalus bubalis) managed under wetland conditions in Argentina: Effect on follicular population, oocyte recovery, and in vitro embryo development. Anim Reprod Sci, 183:39-45.

Kumar D, Anand T. 2012. In vitro Embryo Production in Buffalo: Basic Concepts. Journal of Buffalo Science, 1: $50-54$.

Kumar P, Verma A, Roy B, Rajput S, Ojha S, Anand S, Datta TK. 2012. Effect of varying glucose concentrations during in vitro maturation and embryo culture on efficiency of in vitro embryo production in buffalo. Reprod Domestic Anim, 47(2):269-273.

Mahmoud KGM, Scholkamy TH, Darwish SF. 2015. Improvement of vitrification of in vitro produced buffalo embryos with special reference to sex ratio following vitrification. Iran J Vet Res, 16(4):325-330.

Mandawala AA, Harvey SC, Roy TK, Fowler KE. 2016. Cryopreservation of animal oocytes and embryos: Current progress and future prospects. Theriogenology, 86(7):1637-1644.

Neglia G, Gasparrini B, Caracciolo di Brienza V, Di Palo R, Campanile G, Antonio Presicce G, Zicarelli L. 2003. Bovine and buffalo in vitro embryo production using oocytes derived from abattoir ovaries or collected by transvaginal follicle aspiration. Theriogenology, 59(5-6):1123-1130.

Neglia G, Gasparrini B, Vecchio D, Boccia L, Varricchio E, Di R, Campanile G. 2011. Long term effect of Ovum Pick-up in buffalo species. Anim Reprod Sci, 123(3-4):180-186.

Oba O, Camargos AS. 2011. Produção in vitro de embriões bubalinos. Rev Bras Reprod Anim, 35(2):80-87.

Ocampo MB, De Assis AT, Ocampo LC, Kanagawa H. 1994. Histological observation of follicular atresia in Swamp buffalo. Buffalo Bulletin, 13(3).

Ohashi OM, Nogueira N, Cordeiro S, Filho TR, Francisco H, Ribeiro L, Guimarães TV. 2017. Produção in vitro de embrião ( PIVE ) na espécie bubalina. Rev Bras Reprod Anim, 14(1):195-200.

Palta P, Chauhan MS. 1998. Laboratory production of buffalo (Bubalus bubalis) embryos. Reprod Fertil Dev, 10(5):379-391.

Parnpai R, Liang Y, Ketudat-Cairns M, Somfai T, Nagai T. 2016. Vitrification of buffalo oocytes and embryos. Theriogenology, 86(1): 214-220.

Parrish JJ. 2014. Bovine in vitro fertilization: In vitro oocyte maturation and sperm capacitation with heparin. 
Theriogenology, 81(1):67-73.

Perera BMAO. 2011. Reproductive cycles of buffalo. Anim Reprod Sci, 124(3-4):194-199.

Rath D, Moench-Tegeder G, Taylor U, Johnson LA. 2009. Improved quality of sex-sorted sperm: a prerequisite for wider commercial application. Theriogenology, 71(1):22-29.

Sales JNS, Iguma LT, Batista RITP, Quintão CCR, Gama MAS, Freitas C, Baruselli PS. 2015. Effects of a high-energy diet on oocyte quality and in vitro embryo production in Bos indicus and Bos taurus cows. J Dairy Sci, 98(5):3086-3099.

Saliba W, Gimenes L, Drumond R, Bayão H, Alvim M, Baruselli P, Gasparrini B. 2013. Efficiency of OPU-IVEP-ET of Fresh and Vitrified Embryos in Buffaloes. Buffalo Bulletin, 32(2):385-388.

Santos S do SD, Dantas JK, Miranda M dos S, Biondi FC, Ohashi OM. 2002a. Cinética da maturação nuclear in vitro de oócitos bubalinos. Braz J Vet Res Anim Sci, 39(5):266-270.

Santos SSD, Costa SHF, Dantas JK, Ohashi OM. 2002b. Maturação in vitro de oócitos bubalinos. Rev Bras Reprod Anim, 26(1):37-42.

Santos SSD, Ferreira MAP, Sampaio RV, Costa NN, Santos DCN, Santana PPB, Sá ALA. 2013. Evaluation of apoptosis as a mechanism of follicular cell atresia in the ovaries of cattle ( Bos indicus ) and buffalo ( Bubalus bubalis ) fetuses. Anim Reprod, 10(1):55-61.

Singhal S, Prasad S, Singh B, Prasad JK, Gupta HP. 2009. Effect of including growth factors and antioxidants in maturation medium used for in vitro culture of buffalo oocytes recovered in vivo. Anim Reprod Sci, 113(1-4):44-50.

Suárez Novoa MV, Di Francesco S, Rubessa M, Boccia L, Longobardi V, De Blasi M, Gasparrini B. 2011. Effect of reducing glucose concentration during in vitro embryo culture in buffalo (Bubalus bubalis). Reproduction, Fertility and Development, 23(1):168.

Suresh KP, Nandi S, Mondal S. 2009. Factors affecting laboratory production of buffalo embryos: a meta-analysis. Theriogenology, 72(7):978-985.

Totey SM, Singh G, Taneja M, Pawshe CH, Talwar GP. 1992. In vitro maturation, fertilization and development of follicular oocytes from buffalo (Bubalus bubalis). J Reprod Fertil, 95(2):597-607.

Verma M, Pandey S, Bhat IA, Mukesh B, Anand J, Chandra V, Sharma GT. 2018. Impact of 1-carnitine on lipid content and post thaw survivability of buffalo embryos produced in vitro . Cryobiology, 82:99-105.

Wadhwa N, Kunj N, Tiwari S, Saraiya M, Majumdar SS. 2009. Optimization of embryo culture conditions for increasing efficiency of cloning in buffalo (Bubalus bubalis) and generation of transgenic embryos via cloning. Cloning and Stem Cells, 11(3):387-395.

Yang CY, Pang CY, Yang BZ, Li RC, Lu YQ, Liang XW. 2012. Optimization of cryopreservation of buffalo (Bubalus bubalis) blastocysts produced by in vitro fertilization and somatic cell nuclear transfer. Theriogenology, 78(7):1437-1445. 